Sambulo Ndlovu*

\title{
Attributional and relational influence of numerals in S'ncamtho metaphors
}

https://doi.org/10.1515/lingvan-2019-0067

\begin{abstract}
Youth varieties in Africa such as S'ncamtho, the Ndebele-based youth variety in Zimbabwe, and urban vernaculars interact with urban and modern experiences which offer them new materials and experiences to base their metaphors on compared to older metaphors in the base languages. This paper explores the use of numeral qualities and associations in the conceptualisation and orthographic representation of S'ncamtho metaphors. S'ncamtho is popular with urban youth and this makes social media platforms such as Twitter, Facebook, WhatsApp, SMS and Instagram key in the performance of the youth variety, a performance that includes the creation, use and contraction of metaphors. Numerals offer phonetic attributes which are exploited in S'ncamtho as metaphors for contracting longer words into shorter ones for fast and economic writing on social media. Numerals are also used as frames to create analogies which elicit euphemistic and general S'ncamtho metaphors. Qualities of numerals such as sound, form and association are used to derive S'ncamtho metaphors and a unique numeral aided orthography to represent some of these metaphors in writing. The research deploys relational and attributional tenets of metaphor theory to analyse the numerical mappings in S'ncamtho metaphors.
\end{abstract}

Keywords: S’ncamtho, metaphor, numerals, glyph, social media

\section{Introduction}

This paper analyses how speakers of S'ncamtho the Ndebele-based youth language in Zimbabwe use numerical literacy to derive numeral glyphs in writing. Numeral glyphs that characterise S'ncamtho net speak are derived through phonemic and physical mappings creating instances of glyph metaphors. Youth language is a phenomenon which is closely related to slang and urban vernacular. Kiessling and Maarten (2004) identify several youth languages across Africa and they note that these differ from their base languages in lexes. Youth varieties in Africa and elsewhere are created by stylising lexes through various processes and some of these processes are also present in slang formation. Hurst (2017: 211) notes that: 'while not simply slang, they share some features in common with slang use'. Hurst and Mesthrie (2013) propose stylect as a general term for all youth languages, the varieties are also known by other general terms in South Africa such as tsotsitaal, ringers, isistsotsi and isijita. Hurst (2009) characterises tsotsitaal in South Africa, and avers that tsotsitaal is linguistic performance which utilises a style adopted by many youth living in urban townships in South Africa. The tsotsitaal style is signalled by the unique and innovative lexicon, and in this innovative lexicon numerals are also employed to create youth language lexes especially in Computer Mediated Communication. Zhang (2017) observes that use of numerals in digital communication as a shorthand strategy and language play is common across the world's languages.

The phenomenon of youth languages in South Africa is important in the understanding of S'ncamtho the Ndebele-based youth variety in Zimbabwe, due to the close historical, linguistic and social ties between the Ndebele of Zimbabwe and the Zulu of South Africa. Additionally, many Ndebele speakers work in South Africa

\footnotetext{
*Corresponding author: Sambulo Ndlovu, Department of African Languages and Culture, Great Zimbabwe University, Masvingo, Zimbabwe; and Humbolt Research Fellow- Institut fur Ethnologie und Afrikanstudien at Johannes Gutenberg-Universitat, Mainz, Germany, E-mail: matsilaneg@gmail.com
} 
and even more watch South African television in Zimbabwe. The glottonym S'ncamtho derives from the same source as the name iScamtho for the Zulu-based youth variety in South Africa. Ntshangase (1993:1) posits that the name iScamtho is:

Derived from the (Zulu) verb -qamutha or -qamunda 'to talk volubly or maintain a constant flow of language', and is known to its speakers as iringas (from Eng. 'ring' as in the ring of a telephone), itaal (from Afr. taal i.e. language'), istsotsi (from tsotsi meaning 'a thief or generally 'a young city slick man') or isjita (from umjita young man').

The name S'ncamtho for the Zimbabwean variety was popularised by Ndlovu (2012), who points out that there is nasalisation of the dental click in the way the Ndebele pronounce iScamtho, creating the term S'ncamtho. The name is now established in literature as referring to the Ndebele-based variety. Ndlovu (2018a) uses the term as he looks at the evolution of S'ncamtho greetings over time, Ndlovu (2018b) measures the spread of the S'ncamtho variety to rural environs, while Ndlovu (2018c) evaluates the impact of S'ncamtho on place names within Bulawayo city. Ndlovu (2012) assesses the impact of S'ncamtho metaphors on Ndebele while Ndlovu (2018b) characterises metaphor in S'ncamtho and identifies lexical innovations used to derive S'ncamtho metaphors. The association between youth varieties and education has seen some elements from the school curriculum such as numerals being used to create lexes. The youth in S'ncamtho employ numerals to derive complex meanings and writing systems creating numerical metaphors in the process. Halliday (1976: 578) observes that: 'There are phonological metaphors, grammatical metaphors- morphological, lexical and perhaps syntactic - and semantic metaphors,' in youth varieties.

Numerical metaphors in S'ncamtho are mostly phonological, semantic and lexical. To interpret S'ncamtho texts as metaphorical, one has to delve into the cultural and discourse intricacies in which the metaphors operate (Ndlovu 2018b). Early scholarship on metaphor such as Grice (1975) and Levin (1977) believed metaphorical meaning to be created de novo, excluding pre-existing schemes. However, later developments confirm the opposite. Gibbs (1994), Kovecses (2002) and Lakoff (1987) all argue for the possibility that metaphor is fundamental to language, thought and experience. Lakoff (1993) views metaphor as cross-domain mappings based on thought processes, while Gibbs (1996) argues that a metaphor is not merely a figure of speech but a mental mapping. Metaphor in youth languages also includes euphemisms for tabooed concepts (Horne 2010; Selikov 2004; Suguitan 2005).

There are several lexicalising strategies in youth languages employed in the creation of metaphor. SmithHefner 2007: 192) identifies abbreviation as a lexicalising strategy in Gaul, the youth variety of Indonesia and Horne (2010) demonstrates how youth varieties use numerals to express abbreviations for example the BMW luxury sports car Z3's brand name is used to refer to HIV whereby the \{3\} maps on to the three letters in the abbreviation. Mugaddam (2015) identifies semantic manipulation in Randuk and notes that it manifests mostly as metonymy, the relational extension of meaning. In this way, some metaphors are similarly created in S'ncamtho using numerals. Rüsch and Nassenstein (2016) also describe semantic manipulations as a lexicalising strategy in Lep pa Bulu the Acholi-based Ugandan youth language, while Boutin and Dodo (2018: 55) note that: "in Nouchi, onomastic synecdoche is used to reassign meanings from proper names." In the Zimbabwean context Hollington and Makwabarara (2015) analyse lexicalising strategies in Zimbabwean youth varieties and they identify borrowing, code-switching and mixing, metathesis and morphological hybridisation. Numerals are also employed phonologically, semantically, structurally and relationally to create S'ncamtho metaphors.

The use of numeral homophones as syllables is common practice across the world's languages, including vernaculars and youth varieties. Frehner (2008) avers that numbers often substitute words or part of them in text messages in English based on sound resemblance. Crystal (2008) gives a summary of the use of numerals in text messages in different languages in which they substitute syllables that are homophones to the numerals. He gives the example of the combination of Japanese and English in the Japanese greeting ohayoo [ohajoo] "good morning" numerically represented as $\{0840\}-\{0\}$ (oh English) $\{8\}$ (ha Japanese) $\{4\}$ (yo Japanese) $\{0\}$ (oh English). Nishimura (2006) also identifies the syllabification of numerals in Japanese online writing which he calls rebus writing motivated by word play and a desire to speed up typing. In his analysis of 
French SMSs, Anis (2007) found out that numbers are part of the shortening strategies used to substitute for syllables and he calls this phenomenon "syllabogram" writing which provides for creative and economic expression. Shortis (2009) observes the same in English and notes that number homophones provide for brevity and speed.

According to Herring (2016) numerals do not only substitute syllables based on homophony but there are cases whereby graphic resemblance is employed. In analysing online Greek texts, Tseliga (2007) notes the substitution of the numeral $\{8\}$ for Greek $[\theta]$ due to graphic resemblance and ease of typing; a similar trend is observed in Arabic by Palfreyman and Khalil (2003). Zhang (2017) observes that there is massive use of both Mandarin and Arabic numerals in Chinese online communication for non-numerical functions; he argues Arabic numerals are favoured to overcome the clumsy Chinese character input system.

The association of S'ncamtho with the new media has created an increased need for shorthand writing and this has seen numerals coming in handy to shorten certain words in writing. The shortening of words using numerals is based on phonological mappings between the sounds in numerals and the sounds in words. The structure of the numerals is also employed to express some situations which relate structurally to numerals, while certain relational mappings also use numerals as metonyms and meronyms. Bello (2016) identifies mobile phone language as influenced by slang in Nigerian schools and its effect on English learning. S'ncamtho is also used on social media platforms where space is limited and texts are expensive. It utilises numerals to shorten texts and retain the vividness of the expression.

\section{Research methodology}

Data for the research was collected using participant and non-participant observations, unstructured interviews, intuition and from social media platforms of Facebook, Twitter, WhatsApp and SMS. A total of 37 numerical metaphors were collected and their meanings and etymologies were discussed in social media focus group discussions and some were verified through interviews. Content analysis is the analytical process used to analyse the numerical metaphors. Content analysis is used to analyse meanings and relationships in texts. Krippendorff (1989:403) argues:

Content analysis is indigenous to communication research and is potentially one of the most important research techniques in the social sciences. It seeks to analyse data within a specific context in view of the meanings someone- a group or a culture attributes to them. Communications, messages, and symbols differ from observable events, things, properties, or people in that they inform about something other than themselves; they reveal properties of their distant producers or carriers, and they have cognitive consequences for their senders, their receivers, and the institutions in which their exchange is embedded.

Numerical metaphors and indeed all metaphors can be analysed using content analysis because it focuses on context and emphasises the cognitive consequences of a text to both sender and receiver. The cognitive effects of metaphors are realised through stimulus equivalence and the mappings are culturally and contextually governed.

\section{Theoretical framework}

This study deploys a conceptual metaphor theory to analyse the use of numerals in S'ncamtho discourse. Tenets of the Relational Frame Theory (RFT) of metaphor are employed to qualify some instances of numeral usage in S'ncamtho as creation and conceptualisation of metaphor. RFT derives from theorising human language from a psychological standpoint. The theory was developed by Hayes (1991), and is premised on relating human experiences one to another as a way of creating human cognition and ultimately human language. It argues for a bidirectional link between things to create human language. Stewart and Barnes-Holmes (2001:193) describe how: 'RFT uses concepts of equivalence and transfer of function to analyse metaphor conceptually and empirically’. RFT focuses on stimulus equivalence and it 
builds on research in human behaviour, language and learning. Chomsky's (1957) work on generative grammar deals with novel and derived abilities in human language, and this stimulated researchers such as Keane (1988) to focus on deductive and analogical reasoning, and also led to an interest in cognitive development (Piaget 1967). The interest in cognition and language led Sidman (1994) to develop the concept of stimulus equivalence and Hayes et al (2001) aver that related effects of stimulus equivalence are relational frames.

Stimulus equivalence results in relational responding and RFT emphasises the importance of context for stimulus equivalence to function. Stewart and Barnes-Holmes (2001: 192) view RFT as: "an approach to language and cognition that treats phenomen[a] as arbitrarily applicable relational responding". Human language appears to specify the type of relation and the dimensions along which the types can be related so as to create strong links between two concepts. The theory argues that humans learn language through interacting with the environment and according to Hayes and Brownstein (1986) such learning is based on functional contextualism. Stewart and Barnes-Holmes (2001) aver that frames used in functional contexts can be combined to derive complex cognitive and verbal phenomena such as metaphor. Barnes-Holmes et al. (2004: 188) also note that: 'the importance of physical properties in the natural environment as possible sources of contextual control over patterns of relational responding, is heavily emphasised in RFT'. Homophone and image schema are instances of physical properties applied on numerals to derive relational responding.

\section{S'ncamtho shorthand numerical glyphs as phonemic metaphor mappings}

Limited space on social media platforms prompted S'ncamtho to develop a shorthand writing system which employs sound correspondence between graphemes to shorten words in writing. The sound correspondence is a type of stimulus equivalence whereby the two graphemes share the same auditory stimuli, and the matched sounds resemble each other. Cruse (2000: 112) argues: 'most youth languages reveal numerous examples of metaphoric speech which can be understood as a figurative connection between two concepts based on a certain resemblance'. The connection between graphemes which share a phonetic quality can be exploited figuratively to create glyph metaphors in writing. S'ncamtho identifies sound correspondences between numerals and some phonemes, and replaces the corresponding phonemes with numerals in writing words which bear the sounds. Common numeral glyphs in S'ncamtho writing are $\{2,4,5,8$ and 9$\}$. The numerals $\{2\}$ and $\{4\}$ are used as wholes, while for $\{5,8$ and 9$\}$ only parts of the numeral sounds are used to map on to corresponding sounds in words.

The numeral $\{2\}$ written as two [tu:] is used as a whole in S'ncamtho shorthand writing as a metaphor for the sound [tu] and its longer counterpart [tu:]; all the phonemes in the numeral are used to map the sound in words. The numeral is used in both English and Ndebele words to replace corresponding sound stimuli. The sound [tu:] in the numeral $\{2\}$ corresponds to similar sounds in the following words; 'tomorrow' [tumoro], 'tonight' [tunait], 'to' [tu], 'today' [tude], thuvi [tu:vi] 'faeces', thula [tula] 'keep quiet' and the sound [tu] in the words is replaced by the numeral $\{2\}$ as in; $2 m r w$ 'tomorrow', 2nyt 'tonight', 2 'to', 2day 'today', $2 v$-thuvi 'faeces', 2la-thula 'keep quiet'. Tagg and Paul (2010) identify the similar use of the numeral \{2\} among British people aged 19 to 68 who use the number homophones in SMS communication, such as using \{2\} [tu:] "2gether" [tugeða] 'together'. 'Four' [fo:] is another numeral used as a glyph in S'ncamtho writing; all the phonemes in [fo:] are mapped on to corresponding sounds in words and the numeral glyph is then used in the place of the matching sounds. The sound [fo:] for numeral $\{4\}$ corresponds to sounds in the following words and is used as a glyph: 4-'for' [fo], 4n-'phone' (noun) [fon], 4na-fona [fona] ('to phone' (Ndebele verb), 4to-'photo' [foto], 4koffokof [fokof] 'fuck off'.

In the case of the numerals $\{5,8$ and 9$\}$, the sound attributes are not all the phonemes in the numerals but part of the phonemes. In Chinese the numeral \{5\}, homophone [wu] is used to replace the syllable; Zhang (2017) 
alludes to numeral homophones in online Mandarin and gives the example of $\{55\}$ [wǔwǔ], which mimics the sound of weeping. However, in S'ncamtho the numeral \{5\} [faiv] pronounced in Zimbabwean English as [fajif] is used as a numerical glyph to represent the sound [faji] (the final [f] phoneme is excluded in the sound mappings) and words that have the sound [faji] as part of their phonemes are written with the numeral $\{5\}$ representing [faji] such as in fine [fajin] and fight [fajit]. The numeral $\{5\}$ is then used to replace the sound [faji] as follows; 5n-fayini 'fine' and 5t-fayithi 'fight'. The numeral eight $\{8\}$ [eit], pronounced as [ejit] in Zimbabwean English is also used in Chinese, Yang (2007) gives the example of $\{88\}$ [bābā] as used by the Chinese for 'byebye' [bacbac] in English because $\{8\}$ in Chinese is pronounced as [bā] which maps on to 'bye'. However, in S'ncamtho only its last two phonemes [jit] are used to map sounds and the number is used to represent the two which form part of its phonemes in Zimbabwean English. Examples of words with the [jit] sound are [nait] 'night' [najit] and [rait] 'right' [rajit], and the numeral replaces [jit] as in na 8 and $r a 8$ respectively. The numeral $\{8\}$ is also added to the numeral $\{9\}$ [nain] pronounced as [najin] to write the word [nait] 'night' [najit], the sounds [na] are taken from the numeral $\{9\}$ and mapped on to [na] in the word [najit]; both numerals share the sound [ji] and the final sound of the numeral $\{8\}[t]$ maps on to [t] the final sound of the word [najit] and the numerical glyph is 98 -night. The numeral $\{9\}$ is also used alone on the word 'night' as in $9 t$ 'night'. The final sound of the numeral $\{9\}[\mathrm{n}]$ is also mapped on to some words which have a similar ending such as [main] 'mine' [majin] and [fain] 'fine' [fajin] to create the glyphs my9 'mine' and fy9 'fine'. The first two syllables of the numeral $\{9\}[$ naji] are used in the writing of the S'ncamtho word for 'fool' isinayi [isinaji] and the glyphs are isi9isinayi 'fool'.

The mapping of numeral sounds and parts of them onto sounds in words is an instance of relational framing whereby the matched sounds are attributes shared by the numerals and the words, and this makes the matching and the final glyphs in writing instances of attributional metaphor. The equivalence is in the sounds wherein the sounds are transferred to the function of glyphs, and this creates both phonetic and grapheme numerical metaphors.

\section{Numerical image schema in S'ncamtho metaphors}

Numerals are used not only in S'ncamtho glyphs but also in mapping onto the environment using their attribute of shape. This forms the class of structural numerical metaphors in S'ncamtho. The mapping of images across concepts is called image schema. McVee et al. (2005: 535) point out that, schema is organising structures that mediate how we see and interpret the world. They further argue: 'a schema stood between or mediated the external world and internal mental structures; a schema was a lens that both shaped and was shaped by experience'. Numeral shapes are used as image schema in S'ncamtho to express human bodily shapes and human emotions, experiences and conditions. Numeral shapes are used as vehicles to communicate human experiences. Physical attributes of numerals are used as vehicles to express human experiences and attributes, Murphy (1996: 175) notes that: 'in verbal metaphor, there are usually two explicit parts: a topic, which is the entity being talked about, and the vehicle, which is the metaphoric material being predicated of the topic.' Table 1 below gives some numeral shapes used as metaphor vehicles for topics in S'ncamtho.

Ndlovu (2018b) identifies sex and sexuality as one of the common topics in S'ncamtho and it is no surprise that the numerals $\{6,8,9$ and 11$\}$ are used to represent human sexuality, and they all map on to human female sexuality as in the shape and figure of women's breasts, bums and genitalia. Shapes of different numerals are also mapped onto corresponding situations, and the numerals represent the situations metaphorically. Numerals form part of youth culture primarily through schooling. Some numerals are used as euphemisms, for example $Z 3$ which is a brand of BMW car, is used to name HIV, where the numeral $\{3\}$ maps on to the number of letters. The link between luxury cars and HIV is the phenomena of 'sugar daddies' that drive such cars and are thought to spread HIV. Euphemisms are common in S'ncamtho because of the association of youth varieties with tabooed topics (Hurst and Buthelezi 2014). 
Table 1: Numeral shapes used as attributional metaphors in S'ncamtho

\begin{tabular}{|c|c|c|}
\hline Numerals & Structural attributes & S'ncamtho metaphorical referent \\
\hline 9 & Bigger round top and flat bottom & A lady with a big bust and a flat bum \\
\hline 6 & Bigger round bottom and flat top & A lady with a big bum and flat bust \\
\hline 8 & $\begin{array}{l}\text { Round and even distribution between top and bottom } \\
\text { with a thin centre }\end{array}$ & $\begin{array}{l}\text { A lady with an evenly distributed figure between bust and bum } \\
\text { having a slim waist }\end{array}$ \\
\hline $6 \& 9$ & $\begin{array}{l}\text { The numeral six is like the numeral nine turned upside- } \\
\text { down }\end{array}$ & Used to express similarity between concepts \\
\hline 101 & $\begin{array}{l}\text { The numeral zero is the odd one out and trapped be- } \\
\text { tween the two ones }\end{array}$ & $\begin{array}{l}\text { Used to express a difficult situation whereby the zero is in a } \\
\text { difficult situation }\end{array}$ \\
\hline 99 & $\begin{array}{l}\text { If the first nine is turned round the numbers' tops } \\
\text { appear to be facing each other head on }\end{array}$ & Face to face confrontation \\
\hline 11 & Two vertical lines with a gap between them & $\begin{array}{l}\text { Female genitalia, the two ones represent the labia minora and } \\
\text { the gap between them; the vaginal orifice }\end{array}$ \\
\hline
\end{tabular}

\section{Numerals as cross-domain mappings in S'ncamtho}

Numeral shapes are not the only numerical mappings in S'ncamtho metaphors, there are other relational mappings that involve numerals. The use of numerals in one domain can be mapped on to another domain. Lakoff (1993: 207) posits that what constitutes a metaphor is not any particular word or expression. It is the ontological mapping across conceptual domains, from the source domain of, for example, weather - mapping

Table 2: S'ncamtho cross domain numerical metaphors.

\begin{tabular}{|c|c|c|c|}
\hline $\begin{array}{l}\text { S'ncamtho numerical } \\
\text { metaphor }\end{array}$ & Gloss & Source domain and meaning & Target domain mappings \\
\hline 0-0: yizero zero & $\begin{array}{l}\text { It is zero- } \\
\text { zero }\end{array}$ & $\begin{array}{l}\text { Soccer - a 0-0 score line means no team } \\
\text { won }\end{array}$ & $\begin{array}{l}\text { Used to describe phenomena whereby both } \\
\text { parties lose and there is no winner. }\end{array}$ \\
\hline $\begin{array}{l}\text { 10-0: } \\
\text { ukutshayatheninothi }\end{array}$ & $\begin{array}{l}\text { To beat ten } \\
\text { scores to } \\
\text { zero }\end{array}$ & $\begin{array}{l}\text { Soccer - a } 10-0 \text { score line is an easy win } \\
\text { with no strong challenge from the loser }\end{array}$ & $\begin{array}{l}\text { Used to represent situations whereby one per- } \\
\text { son is out-smarted or cheated. }\end{array}$ \\
\hline 0 : zero & Zero & Arithmetic - meaning nothing & $\begin{array}{l}\text { Used to express nothing going well or nothing } \\
\text { gained }\end{array}$ \\
\hline 1: amawani & Ones & $\begin{array}{l}\text { Arithmetic/number line - one is the lowest } \\
\text { on the number line }\end{array}$ & Used to express low spirits \\
\hline 1 and 2: uwanilothu & One and two & $\begin{array}{l}\text { Arithmetic - progression from the first } \\
\text { number to the second }\end{array}$ & $\begin{array}{l}\text { Excreta- here passing urine is seen as the start } \\
\text { of a progression which should end with faecal } \\
\text { matter, hence urinating maps on } 1 \text { and defe- } \\
\text { cating maps on to } 2\end{array}$ \\
\hline $2 \times 2:$ thubhayithu & Two by two & Automobiles - a two wheel drive car & $\begin{array}{l}\text { Human transportation- the two wheels map on } \\
\text { the feet and walking is referred to as } 2 \times 2 \text {. }\end{array}$ \\
\hline $4 \times 4$ : fobhayifo & Four by four & Automobiles - a four wheel drive car & $\begin{array}{l}\text { Human transportation- the four in } 4 \times 4 \text { maps on } \\
\text { to the four wheels of a car and driving is referred } \\
\text { to as } 4 \times 4 \text {. }\end{array}$ \\
\hline 18: ieyitini & An 18 & $\begin{array}{l}\text { Demography - } 18 \text { years is the legal age of } \\
\text { majority in Zimbabwe, an } 18 \text { year old is an } \\
\text { adult with a right to privacy }\end{array}$ & $\begin{array}{l}\text { Sanitation- privacy of adult rights is mapped } \\
\text { onto the privacy in toilet use and } 18 \text { is used to } \\
\text { refer to a toilet. }\end{array}$ \\
\hline $4-5$ & Four-five & Armoury - a $4-5$ is a hand gun & $\begin{array}{l}\text { Human sexuality- the shape and size of the hand } \\
\text { gun maps on to the human penis and it is called } \\
\text { a 4-5. }\end{array}$ \\
\hline
\end{tabular}


cold to the feeling of being indifferent towards someone or ignoring them. Here a system of numerals in one domain is transferred to another. Gentner et al. (2001: 200) argue:

According to Structure-mapping Theory, such relational metaphors convey that a system of relations holding among the base objects also holds among the target objects, regardless of whether or not the objects themselves are intrinsically similar. The centrality of relations during metaphor comprehension has been confirmed by a number of studies. For example, people's interpretations of metaphors tend to include more relations than simple attributes, even for statements that suggest both types of commonalities.

This class of S'ncamtho metaphors deploys relations, not attributes like shape, and this is done using domain specific experiences of numerals. Lakoff (2006: 232) avers: "Metaphors are mappings across conceptual domains [...]. Mappings are not arbitrary, but grounded in the body and in everyday experience and knowledge". Table 2 below gives some S'ncamtho numerical metaphors created through cross domain mappings.

Youth, especially males, are also interested in topics such as soccer and motoring, and these domains are sources for most of the numerical metaphors in Table 2 above. Numerals used to express quantities and qualities in sport and motoring are deployed as metaphor vehicles to express topics in human nature and experience. Youth also process arithmetic and use it to relate numerals to life experiences. Barnes-Holmes et al. (2004: 186) point out that: 'given an appropriate history of multiple exemplar training RFT suggests that verbally-able humans are capable of responding to arbitrary relations between and among stimuli that is, relations not defined by the formal properties of the stimuli involved'. Values and ranges of numbers are related to values and ranges in life to create correspondences on which the numerical metaphors are based. Some numerals are used as part of expressing concepts such as adulthood. The numeral 18 carries the meaning of adulthood and the concept is extended to cover privacy which is a feature of adulthood.

\section{Conclusion}

Youth languages thrive on lexicalisation and they employ different strategies to lexicalise and increase their lexes. The lexicalisation and over lexicalisation create abundant metaphor in youth varieties and there are several strategies of metaphor conceptualisation. Metaphor in youth varieties is created from youth language practices and this has seen many metaphors created based on education, technology and urbanisation. Arithmetic learnt at school has provided S'ncamtho with vehicles to derive both attributional and relational metaphors using numerals. Sounds in numbers are mapped on to sounds in words, with the matching results in numeral glyphs replacing letters to shorten writing. Sound based matches use sound correspondence as a metaphorical attribute to create numeral glyphs and metaphors in writing. The need to shorten writing is necessitated by new media which has limited writing space, and it is also expensive to write long texts. Numeral shapes are also used to derive attributional metaphors in S'ncamtho where individual and combinatorial shapes of numerals are used to derive correspondence to human shapes and experiences. Some numerals are also used across domains to create relational metaphors.

\section{References}

Anis, Jacques. 2007. Neography: Unconventional spelling in French SMS text messages. In Brenda Danet \& Susan C. Herring (eds.), The multilingual internet: Language, culture, and communication online, 87-115. New York: Oxford University Press.

Barnes-Holmes, Dermot, Yvonne Barnes-Holmes, Paul M. Smeets, Veronica Cullinan \& Geraldine Leader. 2004. Relational frame theory and stimulus equivalence: Conceptual and procedural issues. International Journal of Psychology and Psychological Therapy 4(2). 181-214, https://www.redalyc.org/pdf/560/56040202.pdf.

Bello, Yekeen. 2016. An assessment of slang and mobile phone message language use by senior secondary school students in Kwara state, Nigeria: A case for sustainable education advancement. Education Research 9(1). 8-17.

Boutin, Akissi Beatrice \& Jean-Claude Dodo. 2018. View on the updating of Nouchi Lexicon and expressions. In Ellen Hurst-Horash \& Fridah Kanana-Erastus (eds.), African youth languages, 53-73. Palgrave: Macmillan. 
Chomsky, Noam. 1957. Syntactic structures. The Hague: Mouton.

Cruse, Alan. 2000. Meaning in language: An introduction to semantics and pragmatics. Oxford: Oxford University Press. Crystal, David. 2008. Txtng: The gr8 db8. New York: Oxford University Press.

Frehner, Carmen. 2008. Email, SMS, MMS: The linguistic creativity of asynchronous discourse in the new media age. Bern: Peter Lang. Gentner, Dedre, Brian Bowdle, Phillip Wolff, \& Consuelo Boronat. 2001. Metaphor is like analogy. In Dedre Gentner, Keith J.

Holyoak, \& Boicho N. Kokinov (eds.), The analogical mind: Perspectives from cognitive science, 199-253. Cambridge:

Massachusetts Institute of Technology Press.

Gibbs, Raymond W. 1994. The poetics of mind: Figurative thought, language, and understanding. Cambridge: Cambridge University Press.

Gibbs, Raymond W. 1996. Why many concepts are metaphorical. Cognition 61(3). 309-319.

Grice, Herbert Paul. 1975. Logic and conversation. In P. Cole \& J.L. Morgan. (eds.). Syntax and semantics, vol. 3, 41-58. New York: Academic Press.

Halliday, Michael A. K. 1976. Anti-languages. American Anthropologist 78(3): 570-584.

Hayes, Steven. C. 1991. A relational control theory of stimulus equivalence. In Linda J. Hayes \& Phillip N. Chase (eds.). Dialogues on verbal behaviour, 19-40. Reno: Context Press.

Hayes, Steven. C \& Aaron J. Brownstein. 1986. Mentalism, behavior-behavior relations, and a behavior-analytic view of the purposes of science. The Behavior Analyst 9(2). 175-190.

Hayes, Steven. C, Dermot Barnes-Holmes \& Bryan Roche. 2001. Relational frame theory: A post-Skinnerian account of human language and cognition. New York: Kluwer/Plenum.

Herring, Susan C. 2016. Epilogue. In C. Lee (ed.), Multilingualism online, 137-146. New York: Routledge.

Hollington, Andrea \& Tafadzwa Makwabarara. 2015. Youth language practices in Zimbabwe. In Nico Nassenstein \& Andrea Hollington (eds.), Youth language practices in Africa and beyond, 257-270. Berlin: Mouton de Gruyter.

Horne, Felicity. 2010. Slanguage and AIDS in Africa. Language Matters: Studies in the Languages of Africa. 41(1). 25-40.

Hurst, Ellen. 2009. Tsotsitaal, global culture and local style: Identity and recontextualisation in twenty- first century South African townships. Social Dynamics 35(2). 244-257.

Hurst, Ellen. 2017. Rural/urban dichotomies and youth language. In Augustin Ebonguè \& Ellen Hurst (eds.), Sociolinguistics in African contexts: Perspectives and challenges, 209-224. Berlin: Springer.

Hurst, Ellen \& Buthelezi Mthuli. 2014. A visual and linguistic comparison of features of Durban and Cape Town tsotsitaal. Southern African Linguistics and Applied Language Studies 32(2). 185-197.

Hurst, Ellen \& Mesthrie Rajend. 2013. When you hang out with the guys they keep you in style: The case for considering style in descriptions of South African tsotsitaals. Language Matters 44(1). 3-20.

Keane, Mary T. 1988. Analogical problem solving. Chichester: Ellis Horwood.

Kiessling, Roland \& Mous Maarten. 2004. Urban youth languages in Africa. Anthropological Linguistics 46(3). 303-340, https:// www.jstor.org/stable/30028964.

Kövecses, Zoltan. 2002. Cognitive-linguistic comments on metaphor identification. Language and Literature 11(1). 74-78.

Krippendorff, Klaus. 1989. Content analysis. In E. Barnouw, G. Gerbner, W. Schramm, T. L. Worth, \& L. Gross (eds.), International encyclopedia of communication 1. 403-407. New York: Oxford University Press.

Lakoff, George. 1987. The death of dead metaphor. Metaphor and Symbol 2(2). 143-147.

Lakoff, George. 1993. The contemporary theory of metaphor. In Andrew Ortony (ed.), Metaphor and thought, 2nd ed., $202-251$. Cambridge: Cambridge University Press.

Lakoff, George. 2006. Conceptual metaphor. The contemporary theory of metaphor. In Dirk Geeraerts (ed.), Cognitive linguistics: Basic readings, 185-238. Berlin: Mouton de Gruyter.

Levin, Samuel. 1977. The semantics of metaphor. Baltimore: Johns Hopkins University Press.

Murphy, Gregory. L. 1996. On metaphoric representation. Cognition 60(2). 173-204.

McVee, Mary B., Kailonnie Dunsmore \& James R. Gavelek 2005. Schema theory revisited. Review of Educational Research 75(4). 531-566.

Ndlovu, Sambulo. 2012. The S'ncamtho contribution to ndebele idiomatic language change. Paper presented at the 19th Sociolinguistics Symposeium, Freie Universitat Berlin 23-24 August 2012.

Ndlovu, Sambulo. 2018a. Evolution of S'ncamtho greetings: Bulawayo urban youth innovations of greeting genres over time. South African Journal of African Languages 38(3). 285-291.

Ndlovu, Sambulo. 2018b. A comparative analysis of metaphorical expressions used by rural and urban Ndebele speakers: The contribution of S'ncamtho. Cape Town: University of Cape Town PhD dissertation.

Ndlovu, Sambulo. 2018c. Characterisation and social impact of urban youth languages on urban toponymy: S'ncamtho toponomastics in Bulawayo. Literator (Potchefstroom. Online), 39(1). 1-7.

Nishimura, Yukiko. 2006. Linguistic Innovations and Interactional Features of Casual Online Communication in Japanese. Journal of Computer-Mediated Communication, 9. https://doi.org/10.1111/j.1083-6101.2003.tb00356.x (accessed 2 December 2019).

Ntshangase, Dumisani K. 1993. The social history of Iscamtho. Johannesburg: University of the Witwatersrand MA thesis.

Mugaddam, Abdelrahim H.. 2015. Identity construction and linguistic manipulation in Randuk. In Nico Nassenstein \& Andrea Hollington (eds.), Youth language practices in Africa and beyond, 99-118. Berlin: De Gruyter Mouton. 
Palfreyman, David \& Muhamed Al Khalil. 2003. “A funky language for teenzz to use:” Representing Gulf Arabic in Instant Messaging. Journal of Computer-Mediated Communication 9(1). http://onlinelibrary.wiley.com/doi/10.1111/j.1083-6101. 2003.tb00355.x/full (accessed 2 December 2019).

Piaget, Jean. 1967. The child's conception of the world. Totowa: Littlefield, Adams.

Rüsch, Maren \& Nico Nassenstein. 2016. Ethno-regional ideologies and linguistic manipulation in the creation of the youth language Leb Pa Bulu. Critical Multilingualism Studies 4(2). 174-208.

Selikov, Terry-Ann. 2004. "We have our own special language." Language, sexuality and HIV/AIDS: A case study of youth in an urban township in South Africa. African Health Sciences 4(2). 102-108.

Shortis, Tim. 2009. Revoicing Txt: Spelling, vernacular orthography and 'unregimented writing'. In Steve Wheeler (ed.), Connected minds, emerging cultures: Cybercultures in online learning, 225-246. Charlotte: Information Age Publishing.

Sidman, Murray. 1994. Equivalence relations and behaviour: A research story. Boston: Authors Cooperative.

Smith-Hefner, Nancy J. 2007. Youth language, gaul sociability, and the new Indonesian middle class. Journal of Linguistic Anthropology, 17(2). 184-203.

Stewart, Ian \& Dermot Barnes-Holmes. 2001. Understanding metaphor: A relational frame perspective. Behaviour Analysis 24(2). 191-199.

Suguitan, Cynthia Grace B. 2005. A semantic look at feminine sex and gender terms in Philippine gay lingo. 1-11. Available: http:// bangkok2005.anu.edu.au/papers.php (accessed 2 December 2019).

Tagg, Caroline Alistair B. \& Rayson Paul. 2010. “I didn’t spel that wrong did i. Oops”: Analysis and standardisation of SMS spelling variation. Lingvisticæ Investigationes 35(2). 367-388, https://eprints.lancs.ac.uk/id/eprint/60484/1/LI_paper_submitted. pdf.

Tseliga, Theodora. 2007. It's all Greeklish to me!: Linguistic and socio-cultural perspectives on Roman-alphabeted Greek in asynchronous computer-mediated communication. In Brenda Danet \& Susan C. Herring (eds.), The multilingual internet: Language, culture, and communication online, 116-141. New York: Oxford University Press.

Yang, Chunsheng. 2007. Chinese Internet language: A sociolinguistic analysis of adaptations of the Chinese writing system. Language@ Internet, 4. http://www.languageatinternet.org/articles/2007/1142 (accessed 2 December 2019).

Zhang, Yi. 2017. The semiotic multifunctionality of Arabic numerals in Chinese online discourse. Language@Internet, 14(2). https://www.languageatinternet.org/articles/2017/zhang (accessed 2 December 2019). 